\title{
Impact of Nocturnal Noninvasive Ventilation on Pulmonary Rehabilitation in Patients with End-Stage Lung Disease Awaiting Lung Transplantation
}

\author{
Nikolaus Kneidinger ${ }^{\mathrm{a}}$ Rainer Gloeckl ${ }^{\mathrm{b}-\mathrm{d}}$ Ursula Schönheit-Kenn ${ }^{\mathrm{c}, \mathrm{d}}$ \\ Katrin Milger ${ }^{a}$ Wolfgang Hitzle Jürgen Behra Klaus Kenn ${ }^{c, d}$ \\ a Department of Internal Medicine V, Comprehensive Pneumology Center (CPC-M), Member of the German Center \\ for Lung Research (DZL), Ludwig-Maximilians-Universität München, Munich, Germany; ${ }^{b}$ Department for Prevention, \\ Rehabilitation and Sports Medicine, Klinikum Rechts der Isar, Technical University of Munich, Munich, Germany; \\ 'Department of Respiratory Medicine and Pulmonary Rehabilitation, Schön Klinik Berchtesgadener Land, \\ Schönau am Königssee, Germany; ${ }^{\text {d} D e p a r t m e n t ~ o f ~ P u l m o n a r y ~ R e h a b i l i t a t i o n, ~ M e m b e r ~ o f ~ t h e ~ G e r m a n ~ C e n t e r ~ f o r ~}$

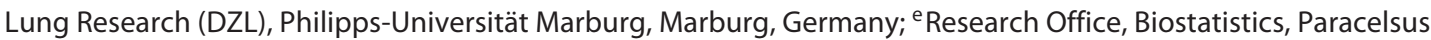 \\ Medical University, Salzburg, Austria
}

\section{Keywords}

Pulmonary rehabilitation · End-stage lung disease $\cdot$ Lung transplantation · Noninvasive ventilation

\footnotetext{
Abstract

Background: Pulmonary rehabilitation (PR) in patients awaiting lung transplantation is crucial to ensure a transplant benefit. However, PR in patients with end-stage lung disease treated with noninvasive ventilation (NIV) remains an area of uncertainty. Objectives: The aim of the study was to assess the potential benefit of PR in patients awaiting lung transplantation treated with NIV. Methods: Patients awaiting lung transplantation who underwent comprehensive inpatient PR from 1998 to 2015 were retrospectively analyzed. Success of PR was assessed by comparing admission and discharge. Multivariate regression models were applied to assess the impact of long-term nocturnal NIV on PR success. Results: In total, 1,044 patients were included in the analysis.
}

Thereof, 296 patients (28\%) were treated with NIV. PR in patients treated with NIV resulted in a significant increase in 6-min walk distance (6MWD; from $250 \pm 117$ to $309 \pm 116$ m; $p<0.0001)$ and in various items of the Short Form Health Survey (SF)-36 questionnaire. The increase in 6MWD was higher in patients treated with NIV than in patients without NIV $(59 \pm 63$ vs. $48 \pm 55$ m; $p=0.003)$. Furthermore, improvements of various lung function variables were higher in patients with NIV. Finally, multivariate generalized regression analysis revealed that NIV therapy was associated with improvement of 6MWD ( $p=0.023)$ while controlling for various baseline characteristics. Conclusions: PR in patients with end-stage lung disease awaiting lung transplantation on nocturnal NIV is feasible and is associated with improvements of exercise capacity and quality of life. Furthermore, despite more advanced lung disease, patients treated with NIV have an increased benefit of PR compared to patients without NIV while awaiting lung transplantation.

(c) 2017 S. Karger AG, Basel

\section{KARGER}

(c) 2017 S. Karger AG, Basel

E-Mail karger@karger.com

www.karger.com/res
Nikolaus Kneidinger, MD, PhD

Department of Internal Medicine V, Comprehensive Pneumology Center (CPC-M) Ludwig-Maximilians-Universität München, Member of the German Center for Lung Research (DZL), Marchioninistrasse 15, DE-81377 Munich (Germany)

E-Mail nikolaus.kneidinger@med.uni-muenchen.de 


\section{Introduction}

Pulmonary rehabilitation (PR) is recommended for patients with chronic respiratory diseases as an adjunct to standard pharmacologic therapy $[1,2]$. Interest in the benefits of PR in patients with end-stage lung disease awaiting lung transplantation is increasing, since maintenance of exercise capacity and muscle mass are critical for survival on the waiting list and for transplant outcome [3-5].

Limited data demonstrate that PR is an effective treatment option for patients on the waiting list for lung transplantation and can improve quality of life and exercise capacity $[6,7]$. There is increasing evidence that even patients with most advanced lung disease benefit from PR despite severely impaired functional status $[8,9]$. Shortterm comprehensive PR can significantly improve exercise capacity in lung transplant candidates to a clinically relevant extent [7].

Noninvasive ventilation (NIV) is used in many patients with end-stage lung disease. Long-term nocturnal NIV has been shown to improve hypercapnia and hypoxemia, quality of life, and neuropsychological function and to reduce hospital admissions and costs [10]. Data suggest that $\mathrm{PR}$ is feasible and effective in patients with chronic lung disease on NIV [11-14]. It has been proposed that NIV as an adjunct to PR improves exercise tolerance and respiratory and cardiovascular performance [15]. NIV augments the benefits of $\mathrm{PR}$ in patients with chronic obstructive pulmonary disease (COPD) with chronic hypercapnic respiratory failure as it improves several measures of health-related quality of life, functional status, and gas exchange [11]. Further, an individually tailored PR plus nocturnal NIV appears to be feasible even in hypercapnic patients with interstitial lung disease (ILD) and significantly improves exercise capacity and quality of life [14].

Currently, no data exist regarding the effect of NIV on PR success in patients with end-stage lung disease listed for lung transplantation. It remains unclear whether PR results in a clinically important benefit in these patients. The aim of the study was to assess the effect of PR in patients with end-stage lung disease awaiting lung transplantation on long-term nocturnal NIV.

\section{Methods}

Design

The study is designed as a retrospective analysis. All patients that were already listed or in evaluation for lung transplantation and underwent comprehensive inpatient rehabilitation between May 1998 and June 2015 were included in the study. All partici- pants completed a multimodal inpatient PR program at the Schön Klinik Berchtesgadener Land (Schönau am Königssee, Germany). Scheduling for PR was elective in all patients, and only those patients were included for whom the 6-min walk distance (6MWD) at admission and discharge was documented during the hospitalization of at least 20 up to 90 days. No further exclusion criteria were specified.

Ethics approval was not indicated, as all of the tests were carried out as part of the clinical routine assessment and analyzed retrospectively out of the anonymized patients' records. The test and therapeutic methodologies used in this study did not change significantly over the study period.

Underlying diseases were categorized into ILD, COPD, cystic fibrosis (CF), and other diseases [16]. In all patients, long-term oxygen therapy and NIV, including NIV application time, inspiratory and expiratory pressures were recorded.

\section{Intervention}

The patients participated in a multimodal inpatient PR. This program included a total of 25-30 therapy sessions, which took place on 5-6 days per week. It consisted of an individualized exercise training program including aerobic exercise and strength training. For aerobic exercise, the patients trained between 10 and $20 \mathrm{~min}$ at $60 \%$ of the peak work rate derived from an initial cycle ergometer test or using an interval training approach exercising at $100 \%$ of the peak work rate and 30-s intervals [17]. Strength training was performed for 3-5 exercises of major muscle groups of the lower and upper extremities performing $3 \times 20$ repetitions with the maximum tolerated load. The intensity of the supervised endurance training sessions was adjusted continuously, with the aim of achieving the maximum tolerated exercise load during each training session [18]. When a drop in oxygen saturation was observed, oxygen was applied to keep oxygen saturation above $88 \%$.

Respiratory physiotherapy consisted of teaching breath control (pursed lip breathing, secretion mobilization, and diaphragmatic breathing), energy saving techniques, and controlled coughing exercises along with activity-of-daily-living exercises. Twice a week ( $1 \mathrm{~h}$ each), all patients participated in educational sessions, which, in addition to self-management, included coping skills and nutrition interventions, self-medication, management of infections and exacerbations, dyspnea, use of oxygen, special lung transplantation-related topics, and activities of daily living. The indication for participating in this comprehensive inpatient $\mathrm{PR}$ was based on evaluation of the impact of the chronic respiratory disorder on different dimensions of health status (e.g., physiological functioning, symptoms, activities, quality of life, and health care utilization) as assessed by general practitioners or other pulmonary centers.

\section{Exercise Capacity}

Exercise capacity was measured at hospital admission and discharge using the 6-min walking test (6MWT), performed once at the beginning and once at the end of the PR program, according to the guidelines of the European Respiratory Society (ERS) [19] and carried out by experienced, well-instructed examiners. The minimal important difference of $30 \mathrm{~m}$ for the 6MWT compared between before and after PR was defined as the primary marker to differentiate between responders and nonresponders [9]. 
Table 1. Assessment of inpatient pulmonary rehabilitation in patients with end-stage lung disease awaiting lung transplantation (all) and patients requiring NIV and awaiting lung transplantation

\begin{tabular}{|c|c|c|c|c|c|c|c|c|}
\hline & \multicolumn{4}{|c|}{ All patients $(n=1,044)$} & \multicolumn{4}{|c|}{ Patients with NIV $(n=296 ; 28.4 \%)$} \\
\hline FEV1, \% predicted & $32.4 \pm 16.3$ & $33.2 \pm 16.5$ & $0.9 \pm 4.7$ & 0.23 & $24.4 \pm 10.5$ & $25.6 \pm 10.7$ & $1.3 \pm 4.2$ & 0.16 \\
\hline VCin, \% predicted & $51.1 \pm 17.9$ & $53.3 \pm 18.1$ & $2.2 \pm 10.2$ & 0.012 & $45.2 \pm 13.8$ & $48.7 \pm 14.4$ & $3.6 \pm 10.1$ & 0.006 \\
\hline FEV1/FVC, \% & $52.8 \pm 23.8$ & $52.2 \pm 22.9$ & $-0.6 \pm 9.8$ & 0.59 & $46.9 \pm 20.2$ & $45.4 \pm 19.7$ & $-1.5 \pm 8.5$ & 0.42 \\
\hline RV/TLC, \% & $67.2 \pm 14.5$ & $66.4 \pm 13.9$ & $-0.8 \pm 7.6$ & 0.20 & $74.4 \pm 11.3$ & $73.1 \pm 10.5$ & $-1.3 \pm 7.2$ & 0.17 \\
\hline 6MWD, m & $285 \pm 127$ & $336 \pm 126$ & $51 \pm 57$ & $<0.0001$ & $250 \pm 117$ & $309 \pm 116$ & $59 \pm 63$ & $<0.0001$ \\
\hline \multicolumn{9}{|l|}{ Health status (SF-36) } \\
\hline Physical functioning & $14.3 \pm 12.4$ & $16.8 \pm 12.9$ & $2.5 \pm 9.4$ & $<0.0001$ & $12.3 \pm 12.3$ & $14.4 \pm 12.5$ & $2.2 \pm 8.7$ & 0.065 \\
\hline Bodily pain & $44.9 \pm 12.7$ & $47.9 \pm 11.5$ & $2.9 \pm 9.9$ & $<0.0001$ & $44.7 \pm 12.2$ & $47.8 \pm 11.4$ & $3.1 \pm 9.9$ & 0.007 \\
\hline Social role functioning & $27.8 \pm 17.2$ & $35.0 \pm 16.5$ & $7.2 \pm 16.5$ & $<0.0001$ & $24.7 \pm 17.2$ & $31.8 \pm 17.9$ & $7.1 \pm 16.9$ & $<0.0001$ \\
\hline Emotional role functioning & $37.3 \pm 18.1$ & $41.6 \pm 17.4$ & $4.2 \pm 18.4$ & $<0.0001$ & $35.6 \pm 18.1$ & $39.4 \pm 18.0$ & $3.7 \pm 17.1$ & 0.053 \\
\hline General mental health & $41.1 \pm 12.8$ & $47.3 \pm 11.6$ & $6.2 \pm 10.0$ & $<0.0001$ & $39.2 \pm 12.3$ & $45.3 \pm 11.5$ & $6.1 \pm 10.8$ & $<0.0001$ \\
\hline Physical summary score & $24.4 \pm 10.2$ & $26.2 \pm 10.4$ & $1.8 \pm 8.3$ & 0.0019 & $23.7 \pm 10.3$ & $25.2 \pm 10.3$ & $1.5 \pm 7.1$ & 0.20 \\
\hline Mental summary score & $42.2 \pm 16.0$ & $50.1 \pm 14.7$ & $8.0 \pm 13.1$ & $<0.0001$ & $39.8 \pm 15.8$ & $48.4 \pm 15.1$ & $8.6 \pm 12.7$ & $<0.0001$ \\
\hline
\end{tabular}

Data are presented as mean \pm SD, unless stated otherwise. Bold type denotes significance. NIV, noninvasive ventilation; FEV1, forced expiratory volume in $1 \mathrm{~s}$; VCin, inspiratory vital capacity; FVC, forced vital capacity; TLC, total lung capacity; RV, residual volume; 6MWD, 6-min walk distance; SF-36, Short Form (36) Health Survey.

Quality of Life

As a standardized health-related quality of life measurement tool, the German version of the Short Form Health Survey (SF)-36 was used. The questionnaire measures 8 dimensions of health-related quality of life and allows calculation of 2 summary scales of physical and mental health. Each scale is directly transformed into a $0-100$ scale on the assumption that each question carries equal weight. A lower score reflects more disability. The higher the score, the less disability, i.e., a score of 0 is equivalent to maximum disability and a score of 100 is equivalent to no disability [20]. Only those questionnaires which were filled in completely and valid were included in the final analysis.

\section{Lung Function and Blood Gas Analysis}

Spirometry and body plethysmography (Master Screen Body; Erich Jaeger GmbH, Höchberg, Germany) were performed on PR admission pursuant to the Guidelines of the American Thoracic Society [21,22] with the use of reference values of the ERS [23]. Blood gases were taken at rest under room air condition (Radiometer ABL800; Radiometer GmbH, Willich, Germany).

\section{Statistics}

Data consistency was checked and the data were screened for outliers and normality by using quantile plots. Data are shown as mean values and standard deviation (SD). The Mann-Whitney U test was used to test for continuous variables between groups and the $\chi^{2}$ test for categorical variables. A generalized multivariate regression model was used to assess the association of NIV with success of PR based on the gamma distribution. A $p$ value $<0.05$ was considered statistically significant. All analyses were done using Statistica 13 (StatSoft, Tulsa, OK, USA) and PASW 20 (IBM SPSS Statistics for Windows; IBM, Armonk, NY, USA).

\section{Results}

\section{Study Population}

In total, 1,044 patients were included in the analysis. The mean age was $51.6 \pm 9.8$ years, 585 patients $(56 \%)$ were female, and the mean body mass index (BMI) was $23.7 \pm$ 5.6. The underlying diseases were as follows: COPD, $n=608$ (58\%); ILD, $n=293$ (28\%); CF, $n=78$ (7.5\%); and other diseases, $n=65$ (6.2\%). Long-term oxygen therapy at rest was used by 912 patients $(87 \%)$ and 296 patients (28\%) were treated with long-term nocturnal NIV. The mean duration of PR was $33.4 \pm$ 15.2 days. 
Table 2. Characteristics of the patients with and those without NIV on admission to inpatient pulmonary rehabilitation $(n=1,044)$

\begin{tabular}{|c|c|c|c|}
\hline & $\begin{array}{l}\text { NIV } \\
(n=296 ; \\
28.3 \%)\end{array}$ & $\begin{array}{l}\text { No NIV } \\
(n=748 ; \\
71.7 \%)\end{array}$ & $p$ value \\
\hline Age, years & $51.8 \pm 9.2$ & $51.5 \pm 10.1$ & 0.59 \\
\hline Female sex, $n(\%)$ & $130(43.7)$ & $330(44.2)$ & 0.95 \\
\hline BMI & $23.2 \pm 5.7$ & $23.9 \pm 5.5$ & 0.057 \\
\hline \multicolumn{4}{|l|}{ Underlying disease, $n(\%)$} \\
\hline COPD & $222(74.8)$ & $386(51.7)$ & $<0.0001$ \\
\hline ILD & $37(12.5)$ & $256(34.3)$ & $<0.0001$ \\
\hline $\mathrm{CF}$ & $26(8.8)$ & $52(7.0)$ & 0.36 \\
\hline Others & $11(3.7)$ & $54(7.2)$ & 0.033 \\
\hline \multicolumn{4}{|l|}{ Lung function testing } \\
\hline FEV1, \% predicted & $24.5 \pm 10.8$ & $35.7 \pm 17.2$ & $<0.0001$ \\
\hline VCin, \% predicted & $45.5 \pm 13.8$ & $53.2 \pm 18.7$ & $<0.0001$ \\
\hline FEV1/FVC, \% & $46.9 \pm 20.2$ & $55.7 \pm 24.8$ & $<0.0001$ \\
\hline TLC, $\%$ predicted & $128.1 \pm 38.5$ & $109.4 \pm 42.2$ & $<0.0001$ \\
\hline $\mathrm{RV}, \%$ predicted & $286.7 \pm 103.3$ & $219.7 \pm 114.4$ & $<0.0001$ \\
\hline RV/TLC, \% & $74.4 \pm 11.3$ & $64.3 \pm 14.6$ & $<0.0001$ \\
\hline DLCO, $\%$ predicted & $23.2 \pm 13.7$ & $29.1 \pm 15.8$ & $<0.0001$ \\
\hline $\mathrm{pCO}_{2}, \mathrm{~mm} \mathrm{Hg}$ & $48.9 \pm 8.1$ & $40.4 \pm 6.1$ & $<0.0001$ \\
\hline $6 \mathrm{MWD}, \mathrm{m}$ & $250 \pm 117$ & $299 \pm 128$ & $<0.0001$ \\
\hline \multicolumn{4}{|l|}{ Health status (SF-36) } \\
\hline Physical functioning & $12.6 \pm 12.0$ & $14.9 \pm 12.5$ & 0.015 \\
\hline Bodily pain & $45.2 \pm 12.3$ & $44.8 \pm 12.9$ & 0.70 \\
\hline Physical role functioning & $26.1 \pm 9.3$ & $26.9 \pm 9.8$ & 0.31 \\
\hline General health perceptions & $30.6 \pm 8.4$ & $30.5 \pm 8.7$ & 0.90 \\
\hline Vitality & $32.6 \pm 10.6$ & $34.3 \pm 10.6$ & 0.037 \\
\hline Social role functioning & $24.5 \pm 16.8$ & $28.8 \pm 16.9$ & 0.0008 \\
\hline Emotional role functioning & $35.4 \pm 18.3$ & $37.8 \pm 18.2$ & 0.10 \\
\hline General mental health & $39.2 \pm 12.3$ & $41.8 \pm 12.9$ & 0.006 \\
\hline Physical summary score & $24.0 \pm 10.1$ & $24.5 \pm 10.0$ & 0.58 \\
\hline Mental summary score & $40.2 \pm 16.2$ & $42.9 \pm 16.0$ & 0.039 \\
\hline
\end{tabular}

Data are presented as mean $\pm \mathrm{SD}$, unless stated otherwise. Bold type denotes significance. NIV, noninvasive ventilation; BMI, body mass index; COPD, chronic obstructive pulmonary disease; ILD, interstitial lung disease; CF, cystic fibrosis; FEV1, forced expiratory volume in $1 \mathrm{~s}$; VCin, inspiratory vital capacity; FVC, forced vital capacity; TLC, total lung capacity; RV, residual volume; DLCO, diffusing capacity for carbon monoxide; $\mathrm{pCO}_{2}$, partial pressure of carbon dioxide; 6MWD, 6-min walk distance; SF-36, Short Form (36) Health Survey.

\section{Pulmonary Rehabilitation}

The effect of PR was assessed by comparing lung function measures, 6MWD, and the SF-36 scores at admission and discharge. As shown in Table 1, PR resulted in an increase in predicted inspiratory vital capacity (VCin; $+2.2 \%$, from $51.1 \pm 17.9$ to $53.3 \pm 18.1 \%$; $p=0.012)$ and

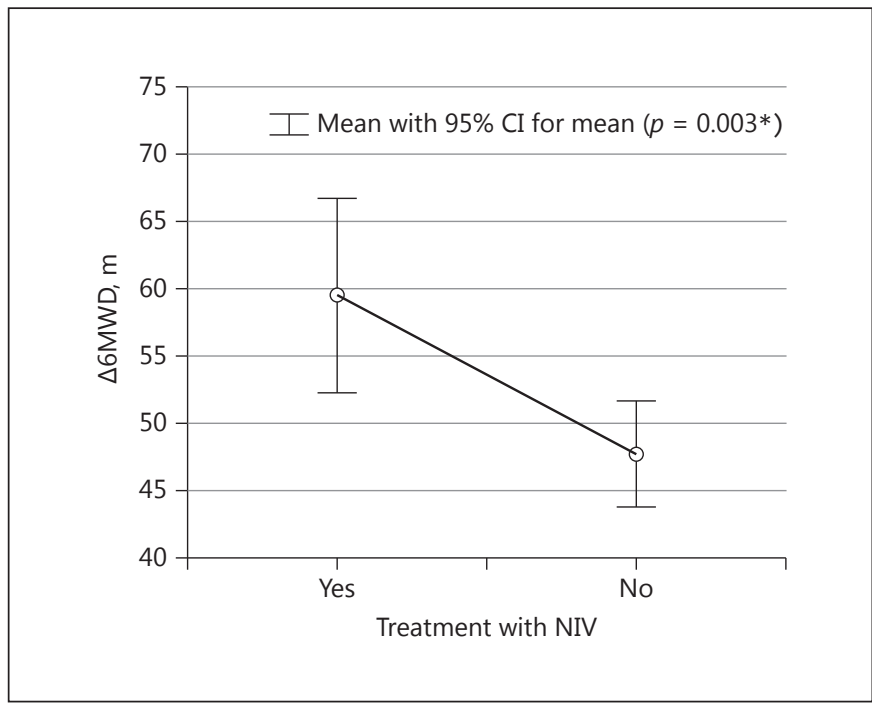

Fig. 1. Increase in 6MWD in patients treated with NIV compared to patients without NIV. 6MWD, 6-min walk distance; NIV, noninvasive ventilation.

in 6MWD (+51 m, from $285 \pm 127$ to $336 \pm 126 \mathrm{~m} ; p<$ $0.0001)$. Further, PR resulted in a significant improvement in all SF-36 domains (Table 1).

\section{PR in Patients Treated with NIV}

To further assess the effect of PR in end-stage lung disease, a subgroup of patients with long-term nocturnal NIV treatment was analyzed. In total, 296 patients (28\%) with NIV were identified. The mean time on NIV was $7.7 \pm 2.6 \mathrm{~h} /$ day. The mean in- and expiratory pressures were $20.6 \pm 4.8$ and $5.3 \pm 1.9 \mathrm{~cm} \mathrm{H}_{2} \mathrm{O}$, respectively. The majority of the patients was female ( $n=167 ; 56.4 \%)$. The mean age was $51.8 \pm 9.1$ years and the mean BMI was $23.2 \pm 5.7$. The diagnoses were as follows: COPD, $n=222$ (75.0\%); ILD, $n=37$ (12.5\%); CF, $n=26$ (8.8\%); and other diseases, $n=11(3.7 \%)$ (Table 2).

$\mathrm{PR}$ in patients with NIV resulted in an increase in predicted VCin $(+3.6 \%$, from $45.5 \pm 13.8$ to $48.7 \pm 14.4 \%$; $p=0.006)$ and in 6 MWD $(+59 \mathrm{~m}$, from $250 \pm 117$ to $309 \pm 116 \mathrm{~m} ; p<0.0001)$. Additionally, $\mathrm{PR}$ resulted in a significant improvement in various items of the SF-36, as shown in Table 1.

Further, the effect of PR in patients treated with NIV was compared to that in patients without NIV (Table 2). Age, sex, and BMI were not different between the groups. However, the patients with NIV suffered more often from COPD (75 vs. $52 \% ; p<0.0001)$ and less often from ILD (13 vs. $34 \%$; $p<0.0001)$ or other diseases (3.7 vs. $7.2 \%$; 
Table 3. Effects on pulmonary rehabilitation in patients treated with NIV compared to patients without NIV $(n=1,044)$

\begin{tabular}{llll}
\hline & $\begin{array}{l}\text { NIV } \\
(n=296 ;\end{array}$ & $\begin{array}{l}\text { No NIV } \\
(n=748 ;\end{array}$ & $\begin{array}{l}p \\
\text { value }\end{array}$ \\
& $28.3 \%)$ & $71.7 \%)$ & \\
\hline Lung function testing & & & \\
$\Delta$ FEV1, \% predicted & $1.3 \pm 4.2$ & $0.8 \pm 4.9$ & 0.12 \\
$\Delta$ VCin, \% predicted & $3.6 \pm 10.1$ & $1.7 \pm 10.1$ & $\mathbf{0 . 0 1 4}$ \\
$\Delta$ FEV1/FVC, \% & $-1.5 \pm 8.5$ & $-0.3 \pm 10.2$ & 0.11 \\
$\Delta$ TLC, \% predicted & $-2.1 \pm 15.7$ & $0.1 \pm 12.5$ & $\mathbf{0 . 0 1 8}$ \\
$\Delta$ RV, \% predicted & $-11.1 \pm 51.0$ & $-1.8 \pm 38.3$ & $\mathbf{0 . 0 0 2}$ \\
$\Delta$ RV/TLC, \% & $-1.3 \pm 7.2$ & $-0.7 \pm 7.1$ & 0.27 \\
$\Delta$ pCO, mm Hg & $0.0 \pm 5.2$ & $0.3 \pm 4.4$ & 0.57 \\
\hline$\Delta 6 \mathrm{MWD}$, m & $59 \pm 63$ & $48 \pm 55$ & $\mathbf{0 . 0 0 3}$ \\
\hline$\Delta$ Health status (SF-36) & & & \\
Physical functioning & $2.2 \pm 8.7$ & $2.5 \pm 9.6$ & 0.66 \\
Bodily pain & $3.1 \pm 9.9$ & $2.9 \pm 9.9$ & 0.74 \\
Physical role functioning & $2.8 \pm 10.0$ & $3.6 \pm 12.0$ & 0.44 \\
General health perceptions & $1.7 \pm 7.6$ & $2.5 \pm 7.5$ & 0.19 \\
Vitality & $7.8 \pm 10.7$ & $8.2 \pm 10.3$ & 0.65 \\
Social role functioning & $7.1 \pm 16.9$ & $7.2 \pm 16.3$ & 0.94 \\
Emotional role functioning & $3.7 \pm 17.1$ & $4.4 \pm 18.9$ & 0.69 \\
General mental health & $6.1 \pm 10.8$ & $6.2 \pm 9.7$ & 0.93 \\
Physical summary score & $1.5 \pm 7.1$ & $1.9 \pm 8.7$ & 0.57 \\
Mental summary score & $8.6 \pm 12.7$ & $7.8 \pm 13.2$ & 0.48 \\
\hline
\end{tabular}

Data are presented as mean $\pm \mathrm{SD}$, unless stated otherwise. Bold type denotes significance. NIV, noninvasive ventilation; FEV1, forced expiratory volume in $1 \mathrm{~s}$; VCin, inspiratory vital capacity; FVC, forced vital capacity; TLC, total lung capacity; RV, residual volume; 6MWD, 6-min walk distance; SF-36, Short Form (36) Health Survey.

$p=0.033)$. The partial pressure of carbon dioxide $\left(\mathrm{pCO}_{2}\right)$ was high in the patients treated with NIV compared to the patients without NIV $(48.9 \pm 8.1$ vs. $40.4 \pm 6.1 \mathrm{~mm} \mathrm{Hg}$; $p<0.0001$ ). Additionally, several measures of severity of disease were more advanced in the patients treated with NIV, as shown in Table 2. On admission, the scores of various physical and mental health items from the SF-36 questionnaire were worse in the patients treated with NIV (Table 2).

The success of PR in the patients treated with NIV was compared to that in the patients without NIV. As shown in Figure 1 and Table 3, the increase in 6MWD was higher in the patients treated with NIV than in the patients without NIV ( $59 \pm 63$ vs. $48 \pm 55 \mathrm{~m} ; p=0.003$ ). Further, in the lung function test, the improvement in VCin, total lung capacity, and residual volume was higher in the patients with NIV than in the patients without NIV. No dif-
Table 4. Results of the generalized multivariate regression models on improvement in 6MWD

\begin{tabular}{lc}
\hline Input variables & $p$ value \\
\hline Age (years) & 0.30 \\
Sex (female) & 0.58 \\
Underlying disease & $\mathbf{0 . 0 0 9}$ \\
Duration of PR (days) & $<\mathbf{0 . 0 0 0 1}$ \\
6MWD & adm) $(m)$ \\
VCin $_{\text {adm }}(\%)$ & $\mathbf{0 . 0 0 0 1}$ \\
FEV1 $_{\text {adm }}(\%)$ & $\mathbf{0 . 0 0 8}$ \\
Noninvasive ventilation & 0.62 \\
\hline
\end{tabular}

Bold type denotes significance. $\mathrm{PR}$, pulmonary rehabilitation; $6 \mathrm{MWD}_{\mathrm{adm}}, 6$-min walk distance on admission; $\mathrm{VCin}_{\mathrm{adm}}$, inspiratory vital capacity on admission; $\mathrm{FEV}_{1 \mathrm{adm}}$, forced expiratory volume in $1 \mathrm{~s}$ on admission.

ferences in the SF-36 outcomes between the groups were found, as shown in Table 3.

To assess the effect of NIV therapy on PR, a multivariate generalized regression model analysis was performed. As outcome variables, changes in 6MWD, VCin, forced expiratory volume in $1 \mathrm{~s}$ (FEV1), and physical and mental summary scores between admission and discharge were assessed. As input variables, age, sex, underlying disease, duration of PR, 6MWD, VCin, and FEV1 at admission were used. As shown in Table 4, NIV therapy was associated with significant improvement in 6MWD $(p=0.023)$ while controlling for the above-described confounding variables. No influences of NIV on the improvements in VCin, FEV1, and physical and mental summary scores were found (data not shown).

Patients treated with NIV were classified as responders ( $n=203 ; 69 \%)$ or nonresponders $(n=93 ; 31 \%)$ according to the minimal important difference of $30 \mathrm{~m}$ in $6 \mathrm{MWD}$, as shown in Table 5. Responders were more likely to be female ( 47 vs. $31 \% ; p=0.009$ ). The predicted diffusing capacity for carbon monoxide (DLCO) was higher in the responders than in the nonresponders $(25.2 \pm 13.9$ vs. $18.5 \pm 12.2 \% ; p=0.011)$. There was no difference in the degree of hypercapnia (Table 5).

\section{Discussion}

PR in patients with end-stage lung disease awaiting lung transplantation on long-term nocturnal NIV is feasible and is associated with clinically important improvements in exercise capacity and quality of life. Further- 
Table 5. Baseline characteristics of the patients treated with NIV classified as responders or nonresponders $(n=296)$

\begin{tabular}{lccl}
\hline & $\begin{array}{c}\text { Responders } \\
(n=203 ; \\
68.6 \%)\end{array}$ & $\begin{array}{c}\text { Nonresponders } \\
(n=93 ; 31.4 \%)\end{array}$ & $\begin{array}{l}p \\
\text { value }\end{array}$ \\
\hline Age, years & $51.4 \pm 9.4$ & $52.8 \pm 8.6$ & 0.23 \\
Female sex, $n$ (\%) & $96(47.3)$ & $29(31.2)$ & $\mathbf{0 . 0 0 9}$ \\
BMI & $23.3 \pm 5.9$ & $22.8 \pm 5.4$ & 0.51 \\
\hline Underlying disease, $n$ (\%) & & & \\
COPD & $150(73.9)$ & $72(77.4)$ & 0.52 \\
ILD & $25(12.3)$ & $12(12.9)$ & 0.89 \\
CF & $20(9.9)$ & $6(6.5)$ & 0.34 \\
Others & $8(3.9)$ & $3(3.2)$ & 0.76 \\
\hline Duration of PR, days & $36.6 \pm 14.8$ & $37.6 \pm 26.3$ & 0.66 \\
\hline Lung function testing & & & \\
FEV1, \% predicted & $24.5 \pm 10.6$ & $24.5 \pm 11.2$ & 0.95 \\
VCin, \% predicted & $45.6 \pm 14.3$ & $45.3 \pm 12.7$ & 0.90 \\
FEV1/FVC, \% & $47.1 \pm 20.6$ & $46.3 \pm 19.3$ & 0.77 \\
TLC, \% predicted & $125.4 \pm 39.1$ & $134.0 \pm 36.8$ & 0.076 \\
RV, \% predicted & $279.2 \pm 103.2$ & $303.6 \pm 102.2$ & 0.065 \\
RV/TLC, \% & $73.9 \pm 11.5$ & $75.5 \pm 10.8$ & 0.28 \\
DLCO, \% predicted & $25.2 \pm 13.9$ & $18.5 \pm 12.2$ & $\mathbf{0 . 0 1 1}$ \\
pCO, mm Hg & $48.9 \pm 8.0$ & $48.9 \pm 8.4$ & 0.98 \\
\hline 6MWD, m & $244 \pm 122$ & $262 \pm 105$ & 0.20 \\
\hline
\end{tabular}

Data are presented as mean $\pm \mathrm{SD}$, unless stated otherwise. Bold type denotes significance. NIV, noninvasive ventilation; BMI, body mass index; COPD, chronic obstructive pulmonary disease; ILD, interstitial lung disease; CF, cystic fibrosis; FEV1, forced expiratory volume in $1 \mathrm{~s}$; VCin, inspiratory vital capacity; FVC, forced vital capacity; TLC, total lung capacity; RV, residual volume; DLCO, diffusing capacity for carbon monoxide; $\mathrm{pCO}_{2}$, partial pressure of carbon dioxide; 6MWD, 6-min walk distance.

more, despite more advanced lung disease, patients treated with NIV experience a larger benefit from PR than patients without NIV while awaiting lung transplantation.

$\mathrm{PR}$ is highly recommended in patients with chronic lung disease as an adjunct to medical therapy $[2,24]$. Several studies have proven benefits from PR concerning exercise capacity and quality of life $[7,9,25]$. Similarly, in our cohort of more than 1,000 patients awaiting lung transplantation, PR was associated with improvements in 6MWD and all SF-36 domains. Our results further support the usefulness of $\mathrm{PR}$ even in patients with end-stage lung disease. This is of particular interest for patients awaiting lung transplantation, since pretransplant functional status is closely related to transplant outcome [3]. Large studies of the UNOS database have shown that pre- transplant 6MWD is a significant predictor of waitlist mortality [26] and is significantly associated with posttransplant survival $[27,28]$. An improvement in 6MWD and functional status, respectively, by PR while awaiting lung transplantation might therefore directly impact outcome. Further, 6MWD and functional status are part of the lung allocation score to estimate the medical transplant benefit $[29,30]$.

Hypercapnia is common in patients with advanced lung disease and has several detrimental effects [31]. Severe breathlessness limits exercise capacity in patients with hypercapnia and might therefore reduce the benefits from PR. Studies have investigated the beneficial effect of NIV while exercising. NIV applied during walking prevents exercise-induced hypoxemia, improves exercise performance with an increased walking distance, and decreases dyspnea [32]. Therefore, it has been suggested that NIV in combination with PR is effective. The addition of NIV to outpatient PR for 2 years for severe COPD patients with chronic hypercapnic respiratory failure improved their quality of life, mood, dyspnea, gas exchange, exercise tolerance, and lung functional decline [12]. Further, NIV augments the benefits of PR in patients with COPD with chronic hypercapnic respiratory failure, as it improves several measures of health-related quality of life, functional status, and gas exchange [11].

Our data provide evidence that the beneficial effect of NIV on PR is notable already in the context of short-term inpatient rehabilitation. This is of particular interest for lung transplant candidates with an anticipated short waiting time for lung transplantation.

To assess the effect of NIV on PR success, multivariate regression analysis was performed. Despite controlling for age, sex, underlying diseases, lung function impairment, exercise capacity, and the duration of PR, treatment with NIV was independently associated with success of PR, underlining the impact of PR on patients with end-stage lung diseases on NIV.

Several factors might be responsible for the beneficial effect of nocturnal NIV on daytime training. NIV decreases hyperinflation and leads to recovery of the inspiratory muscle function, leading to an improvement in respiratory mechanics $[12,33,34]$. Further, NIV has been shown to improve sleep time and efficiency [35]. Nocturnal hypoventilation may be ameliorated, which allows the respiratory center to be reset, resulting in reduced daytime hypercapnia [33].

Daytime hypercapnia was assessed at admission to and at discharge from PR. As expected, the patients on NIV had significantly higher $\mathrm{pCO}_{2}$ levels than the patients 
without NIV. Despite improvements in 6MWD and lung volume, PR had no effect on $\mathrm{pCO}_{2}$ level. Further, the $\mathrm{pCO}_{2}$ levels at admission were not different between the responders and nonresponders to PR. Thus, an association between degree of hypercapnia and PR success seems unlikely. The nonresponders had a significantly lower DLCO and a trend for a higher residual volume and total lung capacity than the responders. This points towards a role of hyperinflation as a limiting factor for the success of PR in patients with NIV. Further, a reduced DLCO could also be a sign of associated pulmonary vascular disease, which might be another factor with an impact on PR success. Further studies will be needed to elucidate the pathophysiologic roles of these factors.

The results of our study should be interpreted in view of the study's limitations. First, it is retrospective, spanning a long time period. However, we provide data from more than 1,000 patients with end-stage lung disease awaiting lung transplantation. Of these, approximately one-third were treated with long-term nocturnal NIV. Second, there is no control group of patients with chronic hypercapnic respiratory failure without NIV use in addition to $\mathrm{PR}$. Therefore, multivariate regression analysis was used to assess the effect of NIV as an adjunct to PR while controlling for various confounding conditions. Third, the study did not research the mechanism providing the beneficial effect of NIV in addition to PR. This needs to be further investigated in more detail.

In conclusion, PR in patients with end-stage lung disease awaiting lung transplantation on long-term nocturnal NIV is beneficial and should be recommended to each of these patients. The effect of pretransplant PR waiting list and posttransplant outcome has to be further addressed in prospective controlled trials.

\section{References}

1 Spruit MA, Singh SJ, Garvey C, ZuWallack R, Nici L, Rochester C, et al; ATS/ERS Task Force on Pulmonary Rehabilitation: An official American Thoracic Society/European Respiratory Society statement: key concepts and advances in pulmonary rehabilitation. Am J Respir Crit Care Med 2013;188:e13-e64.

2 Rochester CL, Vogiatzis I, Holland AE, Lareau SC, Marciniuk DD, Puhan MA, et al; ATS/ERS Task Force on Policy in Pulmonary Rehabilitation: An Official American Thoracic Society/European Respiratory Society policy statement: enhancing implementation, use, and delivery of pulmonary rehabilitation. Am J Respir Crit Care Med 2015;192:13731386.

3 Weig T, Milger K, Langhans B, Janitza S, Sisic A, Kenn K, Irlbeck T, Pomschar A, Johnson T, Irlbeck M, Behr J, Czerner S, Schramm R, Winter H, Neurohr C, Frey L, Kneidinger N: Core muscle size predicts postoperative outcome in lung transplant candidates. Ann Thorac Surg 2016;101:1318-1325.

4 Banga A, Mohanka M, Mullins J, Bollineni S, Kaza V, Ring S, Bajona P, Peltz M, Wait M, Torres F: Hospital length of stay after lung transplantation: independent predictors and association with early and late survival. J Heart Lung Transplant 2017;36:289-296.

5 Weill D, Benden C, Corris PA, Dark JH, Davis RD, Keshavjee S, Lederer DJ, Mulligan MJ, Patterson GA, Singer LG, Snell GI, Verleden GM, Zamora MR, Glanville AR: A consensus document for the selection of lung transplant candidates: 2014 - an update from the Pulmonary Transplantation Council of the International Society for Heart and Lung Transplantation. J Heart Lung Transplant 2015;34:1-15.
6 Hoffman M, Chaves G, Ribeiro-Samora GA, Britto RR, Parreira VF: Effects of pulmonary rehabilitation in lung transplant candidates: a systematic review. BMJ Open 2017;7:e013445.

7 Kenn K, Gloeckl R, Soennichsen A, Sczepanski B, Winterkamp S, Boensch M, Welte T: Predictors of success for pulmonary rehabilitation in patients awaiting lung transplantation. Transplantation 2015;99:1072-1077.

8 Li M, Mathur S, Chowdhury NA, Helm D, Singer LG: Pulmonary rehabilitation in lung transplant candidates. J Heart Lung Transplant 2013;32:626-632.

9 Spielmanns M, Gloeckl R, Schmoor C, Windisch W, Storre JH, Boensch M, Kenn K: Effects on pulmonary rehabilitation in patients with COPD or ILD: a retrospective analysis of clinical and functional predictors with particular emphasis on gender. Respir Med 2016; 113:8-14.

10 Windisch W, Storre JH, Köhnlein T: Nocturnal non-invasive positive pressure ventilation for COPD. Expert Rev Respir Med 2015;9: 295-308.

11 Duiverman ML, Wempe JB, Bladder G, Jansen DF, Kerstjens HA, Zijlstra JG, Wijkstra PJ: Nocturnal non-invasive ventilation in addition to rehabilitation in hypercapnic patients with COPD. Thorax 2008;63:1052-1057.

12 Duiverman ML, Wempe JB, Bladder G, Vonk JM, Zijlstra JG, Kerstjens HA, Wijkstra PJ: Two-year home-based nocturnal noninvasive ventilation added to rehabilitation in chronic obstructive pulmonary disease patients: a randomized controlled trial. Respir Res 2011; $12: 112$.
13 Borghi-Silva A, Mendes RG, Toledo AC, Malosá Sampaio LM, da Silva TP, Kunikushita LN, Dutra de Souza HC, Salvini TF, Costa $\mathrm{D}$ : Adjuncts to physical training of patients with severe COPD: oxygen or noninvasive ventilation? Respir Care 2010;55:885-894.

14 Dreher M, Ekkernkamp E, Schmoor C, Schönheit-Kenn U, Winterkamp S, Kenn K: Pulmonary rehabilitation and noninvasive ventilation in patients with hypercapnic interstitial lung disease. Respiration 2015;89: 208-213.

15 Ricci C, Terzoni S, Gaeta M, Sorgente A, Destrebecq A, Gigliotti F: Physical training and noninvasive ventilation in COPD patients: a meta-analysis. Respir Care 2014;59: 709-717.

16 Kneidinger N, Milger K, Janitza S, Ceelen F, Leuschner G, Dinkel J, Königshoff M, Weig T, Schramm R, Winter H, Behr J, Neurohr C: Lung volumes predict survival in patients with chronic lung allograft dysfunction. Eur Respir J 2017;49:1601315.

17 Gloeckl R, Halle M, Kenn K: Interval versus continuous training in lung transplant candidates: a randomized trial. J Heart Lung Transplant 2012;31:934-941.

18 Gloeckl R, Marinov B, Pitta F: Practical recommendations for exercise training in patients with COPD. Eur Respir Rev 2013;22:178-186.

19 ATS Committee on Proficiency Standards for Clinical Pulmonary Function Laboratories: ATS statement: guidelines for the six-minute walk test. Am J Respir Crit Care Med 2002; 166:111-117.

20 Bullinger M, Kirchberger I: SF-36 - Fragebogen zum Gesundheitszustand. Göttingen, Hogrefe, 1998. 
21 Wanger J, Clausen JL, Coates A, Pedersen OF, Brusasco V, Burgos F, Casaburi R, Crapo R, Enright P, van der Grinten CP, Gustafsson P, Hankinson J, Jensen R, Johnson D, Macintyre N, McKay R, Miller MR, Navajas D, Pellegrino R, Viegi G: Standardisation of the measurement of lung volumes. Eur Respir J 2005; 26:511-522.

22 Miller MR, Hankinson J, Brusasco V, Burgos F, Casaburi R, Coates A, Crapo R, Enright P, van der Grinten CP, Gustafsson P, Jensen R, Johnson DC, MacIntyre N, McKay R, Navajas D, Pedersen OF, Pellegrino R, Viegi G, Wanger J; ATS/ERS Task Force: Standardisation of spirometry. Eur Respir J 2005;26:319338.

23 Quanjer PH, Tammeling GJ, Cotes JE, Pedersen OF, Peslin R, Yernault JC: Lung volumes and forced ventilatory flows. Report Working Party Standardization of Lung Function Tests, European Community for Steel and Coal. Official Statement of the European Respiratory Society. Eur Respir J Suppl 1993;16: 5-40.

24 Bolton CE, Bevan-Smith EF, Blakey JD, Crowe P, Elkin SL, Garrod R, Greening NJ, Heslop K, Hull JH, Man WD, Morgan MD, Proud D, Roberts CM, Sewell L, Singh SJ, Walker PP, Walmsley S; British Thoracic Society Pulmonary Rehabilitation Guideline Development Group; British Thoracic Society Standards of Care Committee: British Thoracic Society guideline on pulmonary rehabilitation in adults: accredited by NICE. Thorax 2013;68(suppl 2):ii1-ii30.
25 McCarthy B, Casey D, Devane D, Murphy K, Murphy E, Lacasse Y: Pulmonary rehabilitation for chronic obstructive pulmonary disease. Cochrane Database Syst Rev 2015; 2:CD003793.

26 Castleberry A, Mulvihill MS, Yerokun BA, Gulack BC, Englum B, Snyder L, Worni M, Osho A, Palmer S, Davis RD, Hartwig MG: The utility of 6-minute walk distance in predicting waitlist mortality for lung transplant candidates. J Heart Lung Transplant 2017;36: 780-786.

27 Martinu T, Babyak MA, O’Connell CF, Carney RM, Trulock EP, Davis RD, Blumenthal JA, Palmer SM; INSPIRE Investigators: Baseline 6-min walk distance predicts survival in lung transplant candidates. Am J Transplant 2008;8:1498-1505.

28 Castleberry AW, Englum BR, Snyder LD, Worni M, Osho AA, Gulack BC, Palmer SM, Davis RD, Hartwig MG: The utility of preoperative six-minute-walk distance in lung transplantation. Am J Respir Crit Care Med 2015;192:843-852.

29 Egan TM, Murray S, Bustami RT, Shearon $\mathrm{TH}, \mathrm{McCullough}$ KP, Edwards LB, Coke MA, Garrity ER, Sweet SC, Heiney DA, Grover FL: Development of the new lung allocation system in the United States. Am J Transplant 2006;6(pt 2):1212-1227.
30 Kneidinger N, Holzborn J, Czerner S, Weig T, Behr J, Winter H, Neurohr C, Schramm R: Evaluation of short-term outcome after lung transplantation in the lung allocation score era. Thorac Cardiovasc Surg 2015;63:693698.

31 Yang H, Xiang P, Zhang E, Guo W, Shi Y, Zhang S, Tong Z: Is hypercapnia associated with poor prognosis in chronic obstructive pulmonary disease? A long-term follow-up cohort study. BMJ Open 2015;5:e008909.

32 Dreher M, Storre JH, Windisch W: Noninvasive ventilation during walking in patients with severe COPD: a randomised cross-over trial. Eur Respir J 2007;29:930-936.

33 Elliott MW, Mulvey DA, Moxham J, Green M, Branthwaite MA: Domiciliary nocturnal nasal intermittent positive pressure ventilation in COPD: mechanisms underlying changes in arterial blood gas tensions. Eur Respir J 1991;4:1044-1052.

34 Ambrosino N, Montagna T, Nava S, Negri A, Brega S, Fracchia C, Zocchi L, Rampulla C: Short term effect of intermittent negative pressure ventilation in COPD patients with respiratory failure. Eur Respir J 1990;3:502508

35 Meecham Jones DJ, Paul EA, Jones PW, Wedzicha JA: Nasal pressure support ventilation plus oxygen compared with oxygen therapy alone in hypercapnic COPD. Am J Respir Crit Care Med 1995;152:538-544. 